\title{
Evidências entre mídia e suicídio: efeito contágio das produções jornalísticas e ficcionais
}

\author{
Evidence between media and suicide: the contagion effect of journalistic \\ and fictional productions
}

\section{Evidencia entre medios y suicidio: el efecto de contagio de producciones periodísticas y ficticias}

Raquel Carriço Ferreira ${ }^{1, a}$

raquelcarrico@gmail.com | https://orcid.org/0000-0002-7307-5527

Kaippe Arnon Silva Reis ${ }^{1, b}$

kaippereis@gmail.com | https://orcid.org/0000-0003-3547-281X

\footnotetext{
${ }^{1}$ Universidade Federal do Sergipe. São Cristóvão, SE, Brasil.

a Doutorado em Cultura Contemporânea e Novas Tecnologias pela Universidade Nova de Lisboa.

' Graduação em Comunicação Social - Audiovisual pela Universidade Federal de Sergipe.
}

\section{RESUMO}

O fenômeno do efeito contágio na mídia não é novo, mas muito atual. No Brasil a mídia é a terceira maior causa de suicídio em jovens de 15 a 29 anos, e um grave problema de saúde pública. Nesse ensaio desvelamos por meio de uma revisão bibliográfica as evidências que suportam o efeito epidêmico de suicídio na mídia e seus modos de operação por meio de teorias como a de Albert Bandura e sua Teoria da Aprendizagem Social. Tal relação é aqui prestigiada em função dos mais recentes sucessos como 13 Reasons Why e Euphoria, que descrevem o suicídio e comportamentos autodestrutivos de forma curiosamente descuidada. Apontamos como urgente a necessidade de normatização legal da produção e distribuição dessas mensagens nos meios de comunicação social brasileiros, que venha a contemplar os diversos gêneros audiovisuais e, sobretudo, os novos suportes de veiculação caracterizados por seu modelo assincrônico de distribuição de conteúdo.

Palavras-chave: Suicídio; Comunicação social; Jornalismo; Ficção; Efeito contágio. 


\begin{abstract}
The phenomenon of the contagion effect in the media is not new, but very current. In Brazil, the media is the third leading cause of suicide in young people aged 15 to 29, and a serious public health problem. In this text, we unveiled through a bibliographic review the evidence that supports the epidemic effect of suicide in the media and its modes of operation through theories such as that of Albert Bandura and his Theory of Social Learning. This relationship is prestigious here due to the most recent hits such as 13 Reasons Why and Euphoria, which describe suicide and self-destructive behaviors in a curiously careless way. We point out as urgent the need for legal regulation of the production and distribution of these messages in the Brazilian media, which will include the various audiovisual genres and, above all, the new media that are characterized by their asynchronous model of content distribution.
\end{abstract}

Keywords: Suicide; Social communication; Journalism; Fiction; Contagion effect.

\title{
RESUMEN
}

El fenómeno del efecto contagio en los medios no es nuevo, sino muy actual. En Brasil, los medios son la tercera causa principal de suicidio en jóvenes de 15 a 29 años y un grave problema de salud pública. En este texto, revelamos a través de una revisión bibliográfica la evidencia que respalda el efecto epidémico del suicidio en los medios y sus modos de operación a través de teorías como la de Albert Bandura y su Teoría del aprendizaje social. Esta relación es prestigiosa aquí debido a los éxitos más recientes, como 13 Razones Por Qué y Euforia, que describen el suicidio y los comportamientos autodestructivos de una manera curiosamente descuidada. Señalamos como urgente la necesidad de una regulación legal de la producción y distribución de estos mensajes en los medios brasileños, que incluirán los diversos géneros audiovisuales y, sobre todo, los nuevos medios que se caracterizan por su modelo asíncrono de distribución de contenido.

Palabras clave: Suicidio; Comunicación social; Periodismo; Ficción; Efecto contagio.

Contribuição dos autores:

Concepção e desenho do estudo: ambos os autores.

Aquisição, análise ou interpretação dos dados: ambos os autores.

Redação do manuscrito: ambos os autores.

Revisão crítica do conteúdo intelectual: ambos os autores.

Declaração de conflito de interesses: não há.

Fontes de financiamento: não houve.

Considerações éticas: não há.

Agradecimentos/Contribuições adicionais: não há.

Histórico do artigo: submetido: 25 set. 2019 | aceito: 20 maio 2020 | publicado: 30 set. 2020.

Apresentação anterior: não houve.

Licença CC BY-NC atribuição não comercial. Com essa licença é permitido acessar, baixar (download), copiar, imprimir, compartilhar, reutilizar e distribuir os artigos, desde que para uso não comercial e com a citação da fonte, conferindo os devidos créditos de autoria e menção à Reciis. Nesses casos, nenhuma permissão é necessária por parte dos autores ou dos editores. 


\section{INTRODUÇÃO}

Os meios de comunicação de massa possuem grande capacidade de agendamento dos assuntos aos quais as populações dão atenção. Se os meios não têm a capacidade de determinar o que as pessoas pensam, há fortes indícios que eles são bem-sucedidos em fazer com que sua audiência se dedique aos temas explorados por esses. Nesse sentido, as séries 13 Reasons Why e Euphoria ${ }^{\mathrm{ii}}$ nos intrigam por tratar de uma temática delicada de saúde pública, o suicídio, pois, sua representação tem sido associada ao aumento de número de casos reais em inúmeros países como podemos ver no estudo publicado no Journal of the American Academy of Child and Adolescent Psychiatry ${ }^{1}$, em que a primeira série está eminentemente relacionada ao aumento de 28,9\% nos índices de suicídio entre crianças e adolescentes nos Estados Unidos. Com o intuito de explorar como esse 'efeito contágio' ocorre e como deveria ser tratado, realizamos uma revisão narrativa com a descrição de um corpo de conhecimento que evidencia suas relações.

Cerca de 800 mil pessoas cometem suicídio por ano no mundo. Cada suicídio é uma tragédia que afeta famílias, comunidades e tem efeitos duradouros sobre as pessoas deixadas para trás, afirma a Organização Pan-Americana da Saúde Brasil (OPAS Brasil)². O suicídio é entendido como dar a morte a si mesmo, ato de tirar a própria vida. As poucas palavras que refletem o entendimento popular do suicídio não compreendem todo tabu e estigma que existe por trás do encerramento da vida de um indivíduo por ação própria.

A cada 40 segundos uma pessoa comete suicídio, e a cada três segundos há uma tentativa de atentado contra a própria vida ${ }^{1}$. Este número é maior do que o de mortos nos sete primeiros anos da guerra civil da Síria, cuja soma de baixas é de 560 mil, de acordo com levantamento do Syrian Observatory for Human Right (SOHR) divulgado em $2018^{3}$.

O suicídio é a $15^{\text {a }}$ maior causa de mortes no mundo de acordo com a Organização Pan-Americana da Saúde (OPAS). No grupo de jovens de 15 a 29 anos, esta é a segunda maior causa de mortes. A média mundial de mortes por suicídio no mundo é de 14,5 suicídios a cada 100 mil habitantes, sendo que países de baixa ou média renda representam 75\% destes casos, de acordo com a Organização Mundial da Saúde (OMS) $a p u d^{4}$. Dados da OMS mostram que, em 2016, a taxa de suicídios para cada 100 mil habitantes no Brasil foi de 6,1, e esta razão muda quando considerado o gênero: se considerarmos apenas a população masculina, a quantidade de suicídios na proporção de 100 mil habitantes foi de 9,7 mortes, já nas mulheres são 2,8 casos $^{5}$.

De acordo com a Associação Brasileira de Psiquiatria (ABP), os homens têm mais chances de cometerem suicídio do que as mulheres. Apenas no estado de São Paulo, a Fundação Seade constatou que 80\% destas mortes no biênio 2013/14 vitimaram homens. Há estudos europeus que procuram explicar tal relação levando em consideração "taxas menores de dependência de álcool, religiosidade mais pronunciada, maior propensão a buscar ajuda em momentos de crise, percepção precoce dos sinais de depressão e participação mais ativa em redes de apoio social"4 entre as mulheres, mais que entre os homens.

Estima-se que ao menos $17 \%$ dos brasileiros já pensaram em cometer suicídio e que aproximadamente $7 \%$ da população mundial enfrenta o luto em decorrência de um ente que se matou ${ }^{3}$. Cada suicídio causa impacto na vida de pelo menos outras seis pessoas de maneira direta. Um levantamento de Bertolote e Fleischmann $a p u d^{4}$ concluiu que $96,8 \%$ dos casos de suicídio registrados tiveram relação com histórico de doenças mentais no indivíduo.

\footnotetext{
13 Reasons Why [serie] [Internet]. Brian Yorkey, developer. Joseph Incaprera, producer. Brian Yorkey, Diana Son, Tom McCarthy, Joy Gorman Wettels, Steve Golin, Michael Sugar et al, executive producers. Leo Trombetta, editor. California: July Moon Productions, Kicked to the Curb Productions, Anonymous Content, Paramount Television; 2017-2020 [cited 2020 July 10]. 4 seasons, 49 episodies: 49-98 min., sound, colors. Available from: https://www.netflix.com/br/title/80117470.

ii Euphoria [serie] [Internet]. Sam Levinson, creator. Sam Levinson, Drake, Future the Prince, Ron Leshem, Daphna Levin, Tmira Yardeni et al, executive producers. Los Angeles: The Reasonable Bunch, Little Lamb, DreamCrew, TCDY Productions; 2019- [cited 2020 July 10]. 1 season, 8 episodies: 54-61 min., sound, colors. Available from: https://www.netflix.com/br/title/81179693.
} 
Dentro do escopo de distúrbios de ordem mental, os diagnósticos mais frequentes associados a casos de suicídio são depressão (36\%), esquizofrenia (14\%) e transtornos de personalidade (10\%), estes, associados a conflitos, desastres, violências, abusos, perdas e ainda senso de isolamento, fatores que costumam estar ligados ao desenvolvimento das doenças mentais nos casos de suicídio. Há também uma ligação entre suicídio e a dependência de álcool numa ordem de $23 \%$ dos casos, segundo a OMS. "Vale destacar que estamos falando de doenças para as quais existe tratamento, o que significa que o suicídio, em grande parte, pode ser prevenido a partir da adoção de medidas adequadas”.

Apesar das ligações estabelecidas, o Centro de Controle e Prevenção de Doenças (CDC) dos Estados Unidos $a p u d^{6}$ afasta o pensamento simplista de que os casos de suicídio possuem apenas um fator determinante. O CDC, $a p u d^{6}$, alerta que estas mortes são resultado de "uma rede complexa de inúmeros fatores; entre eles, um histórico de problemas psicossociais". Uma característica proeminente do suicídio é que ele é demarcado por alguma tentativa, ou diversas tentativas de interrupção da vida anteriormente. Também estão mais vulneráveis a tal tentativa as pessoas que sofrem discriminação - como LGBTQIA+ +iii, imigrantes e indígenas - e pessoas que vivem em privação de liberdade ${ }^{2}$.

Um estudo do Instituto de Pesquisa Econômica Aplicada (IPEA), de 2013 trouxe resultados que corroboram com outros estudos que buscam entender as motivações para o suicídio. Um deles é o efeito do desemprego sobre as taxas de suicídio de jovens de 15 a 29 anos. Os dados do Instituto também identificaram que o divórcio tem impacto sobre os casos de suicídio, principalmente de homens. Em sua conclusão, o estudo apoia ainda a hipótese de que a violência é incentivadora das taxas de suicídio. "Quanto mais violento for o ambiente do indivíduo, maior será a respectiva taxa de suicídio. Novamente, são as pessoas mais jovens do sexo masculino que estão mais expostas ao risco de suicídio, sob este aspecto"7 (p. 24).

Não são poucas as entidades e autoridades que tentam entender o suicídio dentro do escopo da saúde pública, sobretudo, como forma de prevenir e evitar novos casos. O Manual de Imprensa da $\mathrm{ABP}^{4}$ indica que pontos postos como fundamentais em pesquisas internacionais estão sendo trabalhados para diminuir os índices de mortes por suicídio como o treinamento de profissionais da saúde para identificar e tratar casos de depressão, por exemplo, e o acompanhamento de pacientes internados ou atendidos após casos de tentativa de suicídio.

$\mathrm{A} \mathrm{ABP}^{4}$ também coloca como proposta de prevenção a restrição ao acesso às pessoas vulneráveis do que a instituição chama de "meios letais (armas de fogo, venenos, medicações potencialmente letais, acesso a locais de onde o indivíduo pode se jogar)"(p. 12). Este acesso a armamento é também uma preocupação registrada no

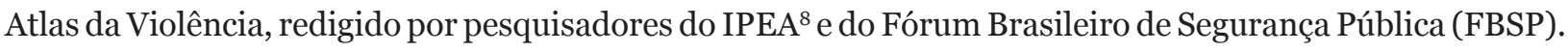
Nesse material, as organizações reafirmam a preocupação da posse de armas de fogo em residências e citam um estudo estadunidense - publicado em 2004, no American Journal of Epidemiology - que indica que o risco de um homem cometer suicídio aumenta 10,4 vezes em casas onde há armas.

Não menos importante, a $\mathrm{ABP}^{4}$ lembra do papel da mídia para a prevenção do suicídio, afirmando que o empenho da imprensa "é fundamental nesse mutirão em defesa da vida" (p. 3). Não é a toa que, em 2016, a instituição lançou a segunda edição do Manual de Imprensa para que pudesse orientar quanto à melhor maneira de abordar o tema na comunicação dando, inclusive, orientações passo a passo de como construir manchetes, como posicionar as matérias, até como explorar o assunto, objetivando a não potencialização de novos casos de suicídio. A produção de um material dedicado diretamente à imprensa é uma medida que já foi tomada também por outras organizações ligadas à saúde como a própria OMS9

iii Sigla que concatena as diversas minorias sexuais e de identidade de gênero significando: Lésbicas, Gays, Bissexuais, Travestis, Transgêneros, Queer, Interssexuais, Assexuais e outras expressões identitárias e sexuais que têm tomado maior visibilidade desde a teoria queer. 


\section{AS EVIDÊNCIAS ENTRE MÍDIA E SUICÍDIO}

A Associação Brasileira de Psiquiatria afirma que a larga propagação de uma reportagem jornalística pode influenciar o aumento dos casos de suicídio ${ }^{4}$, encorajando potenciais suicidas a se empenharem no mesmo comportamento, como os gravemente deprimidos, como afirma Loureiro ${ }^{10}$. A depressão severa como um dos predecessores do suicídio, e em conjunto com outros fatores potencializadores como a mídia, pode ser o gatilho do ato suicida. Este entendimento é apoiado por estudo do IPEA7 que identifica a mídia como a terceira causa de suicídio de jovens de 15 a 29 anos no Brasil.

O estudo 'Os efeitos da mídia sobre o suicídio'7, desenvolvido pelo IPEA, resultou no entendimento de que existem grupos de pessoas que são mais suscetíveis ao suicídio quando expostos ao tema na mídia. Essas pessoas são influenciadas por ideias propagadas nos meios de comunicação digital, como as mídias sociais, bem como por veículos tradicionais como televisão e rádio. O estudo do IPEA apontou que no Brasil, o efeito 'mídia' é o terceiro motivador de suicídios, ficando somente atrás do desemprego e violência. A explicação é que existe um fenômeno de propagação de notícias em canais tradicionais e não tradicionais que disseminam ideias e valores que contagiam as pessoas, e que as encorajaria ao ato suicida que se encontra de alguma forma, já latente. Este processo de encorajamento é conhecido como efeito contágio. Para Loureiro, Moreira e Sachida7 (p. 8), "existe um componente de epidemia em determinados episódios de suicídio".

Em seu manual de prevenção ao suicídio voltado aos profissionais da mídia, a OMS ${ }^{9}$ revela um levantamento de mais de 50 pesquisas realizadas sobre suicídios imitativos. A Organização indica que o pico de contágio por estímulo da mídia acontece nos três primeiros dias de propagação das notícias, influenciando ainda o nível de suicídios nas duas semanas seguintes, e às vezes, até mesmo por um maior período de tempo. Tais correlações se relacionariam à cobertura realizada, ao impacto da história e a propensão ao comportamento suicida ${ }^{9}$.

Nesse sentido, podemos associar o "efeito imitação" à Teoria da Aprendizagem Social do canadense Albert Bandura $^{10,11}$ uma das teorias mais influentes sobre o aprendizado modelado pelos meios de comunicação social. A Teoria da Aprendizagem Social afirma que as pessoas podem aprender a partir da observação de outras pessoas que praticam um determinado comportamento. A chamada aprendizagem observacional explica a natureza das crianças de aprenderem ao observar pessoas ao seu redor, imitando-as. A modelagem de um comportamento exibido nos meios de comunicação pode ocorrer por uma referência que envolve uma pessoa real ou fictícia desempenhando um comportamento, um modelo de instrução verbal ou simbólica, que envolve a sugestão ou descrição de detalhes sobre um comportamento.

Segundo o autor ${ }^{10,11}$, não são somente os fatores externos que afetariam o comportamento do aprendizado, o comportamento final apoiado no processo de aprendizagem dependeria da força intrínseca do indivíduo (seus estados de espírito ou motivação) que vislumbra uma recompensa ao operacionalizar um comportamento aprendido. Desse modo, pessoas que de alguma forma se encontram desejosas em pôr fim ao seu sofrimento encontrariam em conteúdos específicos da mídia, ferramentas de apoio instrucional, moral e emocional para a condução de comportamentos drásticos.

A representação do comportamento suicida reportado pela mídia assim afeta as pessoas de saúde mental e emocional vulnerável, e comportamentos imitativos podem ocorrer. Para Gould apud ${ }^{12}$ a mídia seria um "mecanismo de troca de informações entre suicidas", desse modo, uma rede encorajadora para novos casos de suicídios. De outra forma, uma pessoa vulnerável que tem contato com um suicida retratado na mídia, que partilha virtualmente das mesmas angústias, causas sociais, emoções e condições do retratado, possivelmente atentará contra sua própria vida.

"A influência dos suicidas sobre os potenciais suicidas pode ocorrer por meio de propagação de notícias ou debates na mídia" (p.11) afirmam Loureiro, Moreira e Sachsida7. Esse efeito é observado de maneira ainda mais 
potente quando o fato se volta sobre a morte de uma celebridade. Quando Marilyn Monroe morreu, a taxa de suicídios cresceu 12\% nos Estados Unidos, na prática mais de 200 mortes. Observamos o relato de que havia bilhetes que citavam que o ato suicida era de fato imitação ao que tinha acontecido à atriz, como indica Arehart-Treichel $\operatorname{apud}^{13}$ (p. 243).

Pesquisadores da Universidade de Columbia estudaram os efeitos da divulgação da morte do ator estadunidense Robin Willians - que cometeu suicídio em agosto de 2014 - nos índices de suicídios dos Estados Unidos nos meses subsequentes ao ocorrido. O estudo foi divulgado em 2018 e concluiu que o número de suicídios aumentou quase $10 \%$ em comparação com a série histórica anterior à morte de Willians. Com o ritmo projetado, seriam 16.849 casos de suicídio, mas naquele ano, ocorreram 18690 mortes similares à do ator, um aumento de 1841 mortes $^{14}$. A taxa da influência desta morte $(\approx 10 \%)$ é percentualmente próxima à da morte de Marilyn Monroe (12\%).

A pesquisa ainda chegou a um coeficiente de influência do suicídio de celebridades sobre mortes por contágio. Tais casos aumentariam 0,26 mortes a cada 100 mil habitantes nas semanas subsequentes ao ato suicida de um famoso ${ }^{14}$. No entanto, o risco do efeito contágio na mídia vai além da imitação da morte em si. Há também o risco de que haja uma imitação do método de como os suicidas escolheram para realizar sua ação. Não é à toa que uma das diretrizes do capítulo "Como noticiar" do Manual de Imprensa da $\mathrm{ABP}^{4}$ é "Não fornecer detalhes do método letal nem fotos". No caso Robin Willians, o estudo da Columbia apontou o aumento de número de suicídios por sufocamento - método usado pelo ator - em 32,3\%. Todos os outros métodos combinados cresceram apenas $3,1 \%^{14}$.

\section{SUICÍDIO NA FICÇÃO}

O foco recorrente dos estudos que se debruçam sobre as relações entre saúde pública/suicídio e mídia/comunicação está sobre as situações jornalísticas, majoritariamente sobre as práticas da 'notícia' e 'reportagem'. No geral, os textos fixam-se nesse contexto, longe do entendimento dos conteúdos ficcionais e suicídio. Este é um fato interessante, uma vez que foi a literatura ficcional do escritor alemão Goethe o estopim para o interesse sobre o suicídio na mídia. No seu livro Os sofrimentos do jovem Werther, publicado originalmente em 1774, é narrado a história de um homem que se apaixona por uma mulher, e porque não pôde consumar o seu amor, ele acaba se matando. O livro teria influenciado o suicídio de uma centena de leitores que replicaram tal prática com o mesmo método, e no mesmo local do protagonista. Tal fenômeno foi denominado Efeito Werther ${ }^{4}$ na literatura médica, o qual hoje identificamos como efeito contágio.

Em 'Suicídio e saúde mental na mídia'13, vemos uma possível explicação para que haja tanta atenção para o ramo jornalístico nos escritos sobre suicídio e mídia: "O jornalismo aqui é a área de mídia mais explorada, porque as demais se encontram numa relação com o entretenimento, a arte ou um compromisso maior com o mercado e as atividades comerciais, como é o caso de programas de entretenimento (TV) e as propagandas. O jornalismo tem um compromisso social maior do que as demais mídias, responde à lei da imprensa e a um código de ética, assim como carrega o fardo do "direito à informação" do público; embora também se encontre em uma posição mercadológica e industrial dentro de empresas privadas dependentes do mercado, para a manutenção financeira"13 (p. 242).

O código de ética citado pelos autores privaria, em tese, a disseminação de conteúdo "sensacionalista ou contrário aos valores humanos, especificamente em cobertura de crimes e acidentes”15. No entanto esta não é uma prática recorrente no Brasil, a exemplo do que vimos em 1993, no telejornal Aqui e Agora da emissora SBT, ao transmitir o suicídio de uma jovem de 16 anos ao vivo para todo o país, em que sua mãe, inclusive, fica ciente do fato através de televisão ${ }^{16}$.

A explicação dos pesquisadores faz sentido quando se coloca em pauta o interesse público na cobertura jornalística. No entanto, o interesse comercial de mercado abre espaço para a divulgação da prática do suicídio nos conteúdos ficcionais, em termos que vai de encontro às premissas estabelecidas nos códigos 
de ética da atividade profissional jornalística, Manual da Imprensa da $\mathrm{ABP}^{4}$, bem como do manual para os profissionais de mídia da OMS, uma vez que o "relato de suicídios de uma maneira apropriada, acurada e cuidadosa, por meios de comunicação esclarecidos, pode prevenir perdas trágicas de vidas"9 (p.4).

O seriado Tod eines Schülers (em português, Morte de um estudante) foi exibido na Alemanha no ano de 1981. Nos seis primeiros episódios da série, o suicídio de Claus Wagner era retratado de diversos pontos de vista. Durante o período de exibição, o número de jovens que cometeram suicídio naquele país aumentou 175\%. Estudos indicam a ligação do seriado e as mortes registradas ${ }^{17}$. Séculos depois de, na Alemanha, jovens terem cometido suicídio após a leitura do livro Os sofrimentos do jovem Werther, de Goethe ${ }^{4}$, os produtores e exibidores do seriado demonstram não ter tido o cuidado do acompanhamento dos relatos da história médica acerca da conexão entre produtos ficcionais e suicídio.

Nesse sentido, no manual para os profissionais da mídia, a $\operatorname{OMS}^{9}$ (p. 9), em uma das poucas orientações para as produções ficcionais, sugere que não se utilize indicações diretas às cenas de suicídio, principalmente fazendo referências ao local e método. Esta recomendação, apoiada por um denso conjunto de evidências científicas, ainda hoje é ignorada por grandes provedoras como a Netflix, que na década seguinte, promove a produção da série 13 Reasons Why.

\section{O CASO 13 REASONS WHY}

Em março de 2017, foi lançado na Netflix, uma provedora global de filmes e séries de televisão via streaming, 13 Reasons Why, série baseada no livro de Jay Asher, publicado em 2007 e adaptado por Brian Yorkey para a plataforma. A primeira temporada do seriado estadunidense conta a história da garota de 16 anos, Hannah Baker, no decorrer de 13 episódios, com cerca de uma hora cada. O título, no Brasil traduzido como Os 13 Porquês, faz referência às motivações que teriam levado a protagonista a cometer suicídio, cada uma revelada em gravações de áudio deixadas por Baker, que são ouvidas a cada episódio pelo personagem Clay Jensen. Nas fitas de áudio foram apontadas 'razões' como exclusão social e estupro para o seu suicídio. No último episódio da primeira temporada, é retratada uma cena de três minutos mostrando o método utilizado por Hannah Baker para tirar a sua vida.

A provedora Netflix não divulga a audiência da sua plataforma, mas para termos uma ideia da repercussão de 13 Reasons Why, observamos os dados divulgados pelo Google. Ele foi o seriado mais pesquisado no buscador dos Estados Unidos e o quarto programa mais pesquisado na plataforma no Brasil ${ }^{18}$. Segundo pesquisa estadunidense divulgada na revista JAMA Internal Medicine, as buscas acerca da série não se limitaram a simples informações sobre ela. Um grupo de pesquisadores divulgou em outubro de 2017 um estudo usando a ferramenta Google Trends que monitorou as pesquisas do dia 31 de março até 18 de abril daquele ano para entender o impacto que a série teve em pesquisas sobre suicídio no Google. Em 12 dos 19 dias pesquisados, a pesquisa sobre suicídio foi maior do que o esperado, em comparação a projeções estimadas para o período que levaram em consideração os dados de janeiro a abril de 2017. Ocorreu um aumento na pesquisa de termos como, "como cometer suicídio" (26\%), "cometer suicídio" (18\%) e "como se matar" (9\%). Ao mesmo tempo, ocorreu um aumento no número de pesquisas acerca de conscientização em termos como "prevenção de suicídio" (23\%) e "suicídio de adolescentes" (34\%)

Este estudo não aponta ligação direta entre a série e casos reais de suicídio, mas corrobora com o entendimento do 'efeito do agendamento ou pauta' em que a série abordaria o assunto do suicídio e, assim, seria o gatilho do aumento de pesquisas realizadas sobre o assunto nos buscadores on line. A teoria nos diz que é a mídia que determinaria a quais assuntos damos atenção em detrimento de outros, sua ideia central é que o público tende a dar mais importância aos assuntos que têm exposição nos meios de comunicação, mobilizado assim, suas atenções. A mídia nesse sentido também cumpriria o papel de conector entre os 
acontecimentos no mundo e as imagens destes no nosso imaginário, sobretudo, por meio das notícias, mas nada impede que o mesmo ocorra com as obras de ficção.

Além da capacidade do agendamento dos assuntos que as mídias promovem, encontramos sugestões de que a série estaria relacionada com o aumento de número de suicídios. O Instituto Nacional de Saúde Mental (INSM) em conjunto com hospitais e universidade estadunidenses concluiu que 13 Reasons Why estava associada ao aumento dos índices de suicídio de crianças e adolescentes no Estados Unidos em 28,9\% no mês seguinte da estreia do seriado. O estudo se debruçou sobre os dados dos Centers for Disease Control and Prevention (CDC, Centros de Controle e Prevenção de Doenças) nos anos de 2013 a 2017, localizando vítimas que iam de 10 a 64 anos. Foi concluído que, em 2017, os meses de abril, junho e dezembro tiveram significativo aumento nas taxas de suicídio de indivíduos de 10 a 17 anos. Somente no mês seguinte ao do lançamento, o estudo contabilizou o maior número de mortes do grupo no país em cinco anos ${ }^{1}$.

Entre abril e dezembro de 2017, ocorreram 195 suicídios acima das projeções para o período, segundo o estudo do INSM. O levantamento não identifica o crescimento de suicídio nos grupos cujas faixas etárias não seja de 10 a 17 anos, associação que poderia estar relacionada ao fato do seriado retratar personagens juvenis em idade escolar, bem como ao fato da protagonista, Hannah, ter 16 anos. Esta hipótese leva em consideração estudo de Debord apud Santana ${ }^{20}$ em que "isso aconteceria porque as informações que chegam espetacularizadas na casa do consumidor carregam consigo uma perspectiva cultural com a ideia de que, no que se observa, existem representações fidedignas ou próximas do cotidiano do indivíduo que contribuirão para o seu intelecto" (p. 4). Assim, segundo Santana, haveria uma projeção do indivíduo, pela identificação de similaridades, de uma naturalização dos fatos, situações, sentimentos, intenções e comportamentos.

De acordo com as evidências encontradas, o suicídio é um fenômeno complexo, multifatorial e não decorre de uma causa única. A mídia desempenha um papel significativo para potencializar o seu contágio, independentemente do formato exibido, se jornalístico ou ficcional. O fato é que o contágio parece ser regular para qualquer tipo de conteúdo que pretenda relatar a "angústia de personagens, a violência contra si próprio e o sangue, que muitas vezes preenche a tela, e que são suficientes para sugerir métodos de suicídio àqueles que já pensaram nessa atitude como forma de resolver seus problemas pessoais”13 (p. 255).

A Netflix, quando confrontada com o estudo do INSM, em matéria da BBC News Brasil publicada em maio de 2019, disse estar trabalhando para assegurar uma maneira responsável de tratar esta questão sensível. A assessoria de imprensa da plataforma de streaming alega que uma pesquisa da Universidade da Pensilvânia mostra que estudantes que viram a segunda temporada de 13 Reasons estavam menos propensos a cometer suicídio. Nesta temporada há mensagens de alerta antes dos episódios "em que seu elenco diz que o programa pode não ser adequado para pessoas que enfrentam questões como abuso sexual, vício em drogas e suicídio". Parece que não foi mesmo o suficiente tal esforço já que a plataforma anunciou em julho de 2019, dois anos após o lançamento, a remoção da cena suicida da personagem Hannah Baker, protagonista da trama, após consulta a especialistas.

Na nota, a Netflix diz "seguindo conselho de experts da medicina, incluindo a Dra. Christine Moutier, médicachefe da American Foundation for Suicide Prevention (Fundação Americana para a Prevenção ao Suicídio), decidimos, junto com o criador Brian Yorkey e os produtores de 13 Reasons Why, editar a cena em que Hannah tira a própria vida na primeira temporada" ${ }^{21}$. Maranhão e Belmonte ${ }^{17}$ levantam outro ponto entendido como problemático na série, que é a busca pela culpa da "desesperança da personagem" em outras pessoas do seu círculo social. "Uma culpa que não lhes é justa. Não significa dizer que está tudo bem ser um abusador ou praticar bullying, mas parece reducionista demais apontar culpados específicos para um suicídio" (p.11-12).

Se o seriado alemão Tod eines Schülers aumentou a quantidade de suicídios em seu país, numa época em que havia limitação da disseminação de conteúdo audiovisual, a projeção tomada por uma empresa de âmbito mundial como a Netflix tem sua proporção ampliada. Os dados do Google identificam que o fenômeno repercutiu no Brasil no ano do seu lançamento, e o grau de repercussão da série ganha corpo 
quando adicionado ao fato de que o número de buscas ao Centro de Valorização da Vida (CVV) aumentou 445\% imediatamente após o lançamento de 13 Reasons. A média diária de visitantes únicos do site do Centro aumentou de 2,5 mil de média em março para 6.770 nos primeiros dias de abril. Nos dez primeiros dias de abril daquele ano de 2017, o Centro recebeu 1840 mensagens enquanto no mesmo período do mês anterior foi quase um terço desse valor: 635 . Ao menos cem pessoas citavam a série ${ }^{22}$.

Daher e Baptista ${ }^{13}$ chamam a atenção para o sensacionalismo na produção de material audiovisual que retrata o suicídio: "Cenas e descrições de suicídio [...] atraem a atenção das pessoas, por pura curiosidade humana. E essa curiosidade pode ser vítima da exploração das mídias comerciais, para venderem o seu produto” (p. 261). A preocupação dos autores quanto à exploração mercadológica da pauta é importante. No dia 22 de junho de 2019 a editoria de entretenimento do UOL trouxe como manchete de matéria sobre o novo seriado da HBO: "Euphoria tem cenas explícitas e faz 13 Reasons Why parecer brincadeira"23.

O seriado da concorrente da Netflix retrata a vida adolescente dos Estados Unidos "como um bacanal juvenil forçado até mesmo para os padrões de Hollywood”24, afirma Margot Sanger-Katz e Aaron E. Carroll, do New York Times (NYT) em matéria publicada no O Globo. A forma como a manchete do UOL é construída é uma promessa de aprofundamento em um seriado adolescente que possui problemas. A nova empreitada da HBO parece não ter aprendido com o caso da concorrente e, segundo as jornalistas do NYT, Euphoria em seu primeiro episódio "contém algumas descrições rápidas de suicídio e muito comportamento autodestrutivo" ${ }^{24}$, e infelizmente, as consequências dessa nova produção poderá repetir as já observadas em materiais cuja temática abordada, é similar.

\section{CONSIDERAÇÕES FINAIS}

As pesquisas que buscam entender a conexão entre a comunicação social e o suicídio são claras ao identificar que a mídia produz o chamado efeito contágio que pode encorajar o suicídio de pessoas vulneráveis. Observamos então, nesse sentido, a necessidade de normatização legal da produção e veiculação dessas mensagens nos meios de comunicação social brasileiros, isso, para que sejam minimizadas as consequências prejudiciais à população, um caso claro de saúde pública. Tal trabalho precisa ser ampliado para todos os formatos da comunicação, não ficando esta normatização restrita ao gênero jornalístico, ou mesmo aos meios tradicionais.

Em seu livro Sobre o suicídio, Karl Marx²5é enfático: "A classificação das diferentes causas do suicídio deveria ser a classificação dos próprios defeitos da sociedade” (p. 44). Se no Brasil a mídia é a terceira maior causa de suicídio em jovens de 15 a 29 anos, então há de fato um defeito a ser corrigido, para que, assim, possamos diminuir os índices que afetam a nossa população. A comunicação social é, de fato, fator preponderante sobre a saúde e bem-estar público, bem como pode ser seu algoz. Além de ampliar os estudos sobre o suicídio e a comunicação ficcional, é necessário ampliar seu debate para que legisladores ou entidades de classe se debrucem sobre a questão e normatizem as soluções cabíveis para esse fenômeno não tão novo, mas muito atual.

Encontramo-nos em um momento ápice do consumo de conteúdo audiovisual on line, que é caracterizado como um modelo assincrônico de obtenção de conteúdo, ou seja, é um material passível de ser encontrado e consumido em plataformas acessíveis por meio de quase qualquer dispositivo, a qualquer tempo e por tempo indeterminado, em redes como Youtube, Netflix e GloboPlay. Nesses ambientes não há limite de acesso ao conteúdo por seu usuário, o que vai de encontro à recomendação da $\mathrm{ABP}^{4}$ de exposição não excessiva, repetitiva, bem como sua exploração espetacularizada, inclusive porque, nem toda fonte de comunicação é institucionalizada ou identificável nesse ambiente.

Aqui, 'não repetir a ênfase, nem produzir novas matérias sobre o caso' cai por terra já que o material pode ser consumido ao gosto do usuário das redes digitais. Isso significa dizer que muito embora a Netflix 
tenha alterado as cenas delicadas de 13 Reasons Why, sua versão original pode estar ainda de forma pirata circulando e sendo consumida na rede. Implica também que suas rivais desavisadas estão muito provavelmente fomentando o aumento do número de suicídios reais, indefinidamente, indistintamente, por canais que multiplicam o efeito contágio.

\section{REFERÊNCIAS}

1. Thirteen Reasons Why está ligada a aumento de suicídios entre jovens nos EUA, diz estudo do governo americano [Internet]. BBC News Brasil (BBC). 2019 maio 01 [citado em 2010 jul. 04]. Disponível em: https://www.bbc.com/portuguese/geral-48112247.

2. Folha informativa: suicídio [Internet]. Brasília: Organização Pan-Americana da Saúde Brasil; ago. 2018 [acesso 2019 jun. 30]. Disponível em: https://bit.ly/2ZYOVEl.

3. Syria: 560,000 killed in seven yrs of war, SOHR [Internet]. [place unknown]: Syrian Observatory for Human Rights; 2018 Dec 10 [cited 2019 June 30]. Available from: https://www.syriahr.com/en/108829/.

4. Associação Brasileira de Psiquiatria; Conselho Federal de Medicina. Comportamento suicida: conhecer para prevenir: dirigido para profissionais da imprensa [Internet]. 2. ed. Rio de Janeiro: A Associação; 2016 [acesso em 2019 jul. 01]. Disponível em: https://www.abp.org.br/manual-de-imprensa.

5. Suicide rate estimates, age-standardized estimates by country [Internet]. Geneva: World Health Organization; 2018 July 17 [cited 2019 July 12]. Available from: http://apps.who.int/gho/data/node. main.MHSUICIDEASDR?lang=en.

6. Colucci C. Mais de $90 \%$ dos casos de suicídio estão relacionados a transtornos mentais [Internet]. Folha de S.Paulo (Grupo Folha). 2013 set. 09 [acesso em 2019 jul. 01]. Disponível em: https://bit.ly/3ed8Y7a.

7. Loureiro PR, Moreira TB, Sachsida A. Os efeitos da mídia sobre o suicídio: uma análise empírica para os estados brasileiros [Internet]. Brasília: Rio de Janeiro: Instituto de Pesquisa Econômica Aplicada; 2013 [acesso em 2019 jul. 01]. (Texto para discussão 1851). Disponível em: https://bit.ly/3gPIk5Q.

8. Cerqueira D, Bueno S, coordenadores, Lima RS, Neme C, Ferreira Helder, Alves, PP et al. Atlas da violência 2019 [Internet]. Rio de Janeiro: São Paulo: Instituto de Pesquisa Econômica Aplicada; Fórum Brasileiro de Segurança Pública; 2019 [acesso em 2019 jul. 01]. Disponível em: https://bit.ly/2W9yfZS.

9. Preventing suicide: a resource for media professionals. Geneva: World Health Organization, International Association for Suicide Prevention; 2008.

10. Baran JS, Davis DM. Mass communication theory: foundations, ferment and future. Belmont: Thompson; 2006.

11. Sincero SM. Social learning theory [Internet]. [place unknown]: Explorable; 201125 Jan [cited 2019 Sept 08]. Available from: https://explorable.com/social-learning-theory.

12. Daemon F. "Morri para inspirar vocês": uma análise das narrativas em disputa perpetradas por jovens homicidas/suicidas em ambientes escolares. Rev Eletron Comum Inf Inov Saúde [internet]. 2016 [acesso em 2019 jul. 6];10(4):1-15. Disponível em https://www.reciis.icict.fiocruz.br/index.php/reciis/article/ view/1021/pdf1021.

13. Daher AVS, Baptista MN. Suicídio e saúde mental na mídia. In: Baptista MN. Suicídio e depressão: atualizações. Rio de Janeiro: Guanabara Koogan; 2004. p. 239-262.

14. Fábio AC. O 'efeito contágio' do suicídio de Robin Williams, segundo esta pesquisa [Internet]. Nexo Jornal (Paula Miraglia, Renata Rizzi e Conrado Corsalette). 2018 fev. 20 [acesso em 2019 jun. 23]. Disponível em: https://bit.ly/2OiKyig.

15. Friedrich M, Rebouças E. Suicídio como pauta jornalística: condutas midiáticas e posturas perante a problemática [Internet]. In: $29^{\circ}$ Congresso Brasileiro de Ciências da Comunicação; 2017 set. 03-09; Universidade Positivo, Brasil. São Paulo: Intercom; 2017 [citado em 2019 jun. 19]. Disponível em: https://bit.ly/3gQI3zL. 
16. Castro T. Em 1993, Aqui Agora exibiu suicídio de adolescente e chocou o Brasil [Internet]. São Paulo: Uol, Notícias da TV, Memória da TV; 2014 set. 05 [acesso em 2019 jul. 3]. Disponível em: https:// noticiasdatv.uol.com.br/noticia/televisao/em-1993-aqui-agora-exibiu-suicidio-de-adolescente-e-chocou-obrasil-4722.

17. Maranhão L, Belmonte WB. 'Efeito Hannah Baker': breve abordagem do suicídio na cobertura jornalística e no entretenimento [Internet]. In: $23^{\circ}$ Congresso Brasileiro de Ciências da Comunicação; 2018 jun. 07-09, Fundação Mineira de Educação e Cultura, Brasil. São Paulo: Intercom; 2018 [citado em 2019 jun. 19]. Disponível em: https://bit.ly/3fmt6oT.

18. Série sobre adolescente suicida bate Game of Thrones em buscas na internet [Internet]. São Paulo: Uol, Notícias da TV, Balanço 2017; 2017 dez. 12 [acesso em 2019 jul. 03]. Disponível em: https:// noticiasdatv.uol.com.br/noticia/series/serie-sobre-adolescente-suicida-bate-game-thrones-em-buscas-nainternet--18205?cpid=txt.

19. Ayres J, Althouse BM, Leas EC, Dredze M, Allem J. Internet searches for suicide following the release of 13 Reasons Why. JAMA Intern Med [Internet]. 2017 Oct 1;177(10):1527-152 [cited 2019 July 20]. Available from: https://bit.ly/38MiGMI.

20. Santana PHB. A série '13 Reason Why' e a circulação da pauta suicídio [Internet]. In: Congresso Internacional Comunicação e Consumo; 2018 out. 08-10, Escola Superior de Propaganda Superior e Marketing, Brasil. São Paulo: Escola Superior de Propaganda Superior e Marketing; 2018 [citado em 2019 jun. 19]. Disponível em: https://bit.ly/2W9TgU1.

21. Moraes F. 13 Reasons Why: Netflix altera cena de suicídio na primeira temporada [Internet]. Brasília: Metrópoles, Entretenimento; 2019 jul. 16 [acesso em 2019 ago. 24]. Disponível em: https://www. metropoles.com/entretenimento/televisao/13-reasons-why-netflix-altera-cena-de-suicidio-na-primeiratemporada.

22. Diógenes J, Toledo LF. Busca por centro de prevenção ao suicídio cresce $445 \%$ após série [Internet]. Estadão (Editora Abril). 2017 abr. 11 [acesso 2019 jul. 3]:Saúde. Disponível em: https://saude. estadao.com.br/noticias/geral,busca-por-centro-de-prevencao-ao-suicidio-cresce-445-apos-serie-danetflix,70001734246.

23. Amendona B. Euphoria tem cenas explícitas e faz 13 Reasons Why parecer brincadeira [Internet]. São Paulo: Uol, Filmes e Séries; 2019 jun. 22 [acesso em 2019 dez. 05]. Disponível em: https://bit. Iy/2CnZokM.

24. Sanger-Katz M, Carroll AE. 'Geração careta': ao contrário do que mostra série 'Euphoria', da HBO, jovens americanos estão fazendo menos sexo e usando menos drogas [Internet]. O Globo (Grupo Globo). 2019 jun. 24 [acesso em 2019 jul. 03]:Sociedade. Disponível em: https://glo.bo/3gO11qM.

25. Marx Karl. Sobre o suicídio. São Paulo: Boitempo Editorial; 2015.

26. Loureiro G. 6 sinais de comportamento suicida. Galileu [Internet]. 2014 out. 22 [acesso em 2019 ago. 25];Sociedade. Disponível em: https://revistagalileu.globo.com/Sociedade/noticia/2014/10/6-sinais-decomportamento-suicida.html. 